\title{
Role of Calyx Lobes in Gas Exchange and Development of Persimmon Fruit
}

\author{
K. Yonemori, A. Itai ${ }^{1}$, R. Nakano, and A. Sugiura \\ Laboratory of Pomology, Faculty of Agriculture, Kyoto University, Sakyo-ku, Kyoto 606-01, Japan
}

Additional index words. Diospyros kaki, fruit growth, respiration, ripening

\begin{abstract}
The role of calyx lobes in $\mathrm{CO}_{2}$ exchange in persimmon (Diospyros kaki Thunb.) fruit was investigated during fruit growth and development. Carbon dioxide exchange rates of attached and detached fruit were measured in light and dark conditions in the field after calyx lobes were removed. Calyx lobes were removed at fruit growth stages I and III, which were defined as the period when fruit diameter increases $>0.3 \mathrm{~mm} \cdot \mathrm{d}^{-1}$ (Zheng et al., 1990). Removing calyx lobes at stage I significantly inhibited fruit growth, while removing them at stage III had no effect on growth. Two weeks after calyx lobes were removed at stage $\mathrm{I}, \mathrm{CO}$ exchange decreased $80 \%$ in light and dark conditions compared with the control fruit. The rapid decreases of $\mathrm{CO}_{2}$ exchange rate by calyx lobe removal at stage I were obvious if expressed per fruit or on a fresh weight basis. In contrast, treatment at stage III had no effect on $\mathrm{CO}_{2}$ exchange rate of fruit and no effect on fruit growth. However, when the calyx lobe scars were sealed with Vaseline soon after calyx lobe removal at stage III, an immediate decline in $\mathrm{CO}_{2}$ exchange rate in the dark occurred with simultaneous inhibition of the final swell in fruit growth. A possible relationship between fruit growth potential and gas-exchange capacity is discussed.
\end{abstract}

Removing calyx lobes from persimmon fruit significantly inhibits fruit growth (Kitagawa and Glucina, 1984). When the calyx lobes are removed at early growth stages, the fruit do not develop to marketable size. The importance of the calyx on fruit growth was also reported in 'Golden Delicious' apple by Westwood (1978). He showed a severe reduction in length : diameter (L/D) ratio of the 'Golden Delicious' fruit if the entire calyx cap was removed at full bloom.

Growth inhibition by calyx lobe removal from persimmon fruit is related to changes in sugar metabolism (Hirano et al., 1995; Yonemori et al., 1995). 'Hiratanenashi' fruit with lobes removed accumulated more sucrose and less glucose and fructose than control fruit (Yonemori et al., 1995). This shift in sugar accumulation may be caused by inhibition of acid invertase activity (Hirano et al., 1995). We showed a rapid increase in acid invertase activities during growth stage III in control fruit, while the activity in treated fruit stayed at low levels. Since sucrose is the main transport sugar in persimmon (Zimmermann and Ziegler, 1975), we have hypothesized that growth inhibition was induced by poor assimilate transport due to an unfavorable sucrose concentration gradient between source and sink organs (Hirano et al., 1995; Yonemori et al., 1995).

However, we don't know why calyx lobe removal inhibits the rise in invertase activity at growth stage III. Protein content of persimmon fruit increases with the onset of growth stage III (Taira et al., 1987). The increase in invertase activity at this stage could be due to de novo synthesis of invertase during the maturation process.

Many stomata are distributed on the calyx lobes, but not on the fruit surface. Calyx lobe removal may reduce the surface area for fruit gas exchange, which, in turn, may inhibit de novo synthesis of protein by reducing respiration. This may account for the inhibition of the acid invertase activity rise at stage III. The objective of this report is to clarify whether the gas exchange of the

Received for publication 25 July 1995. Accepted for publication 28 Feb. 1996. This work was supported, in part, by grant-in-aid (no. 03454046) from the Ministry of Education, Science and Culture, Japan. We thank D.S. Fujii, Dept. of Pomology, Univ. of California, Davis, for correcting English text. The cost of publishing this paper was defrayed in part by the payment of page charges. Under postal regulations, this paper therefore must be hereby marked advertisement solely to indicate this fact. ${ }^{1}$ Present address: Laboratory of Horticulture, Faculty of Agriculture, Tottori Univ., Tottori 680, Japan. persimmon fruit is affected by calyx lobe removal and/or whether it has an important role in persimmon fruit development.
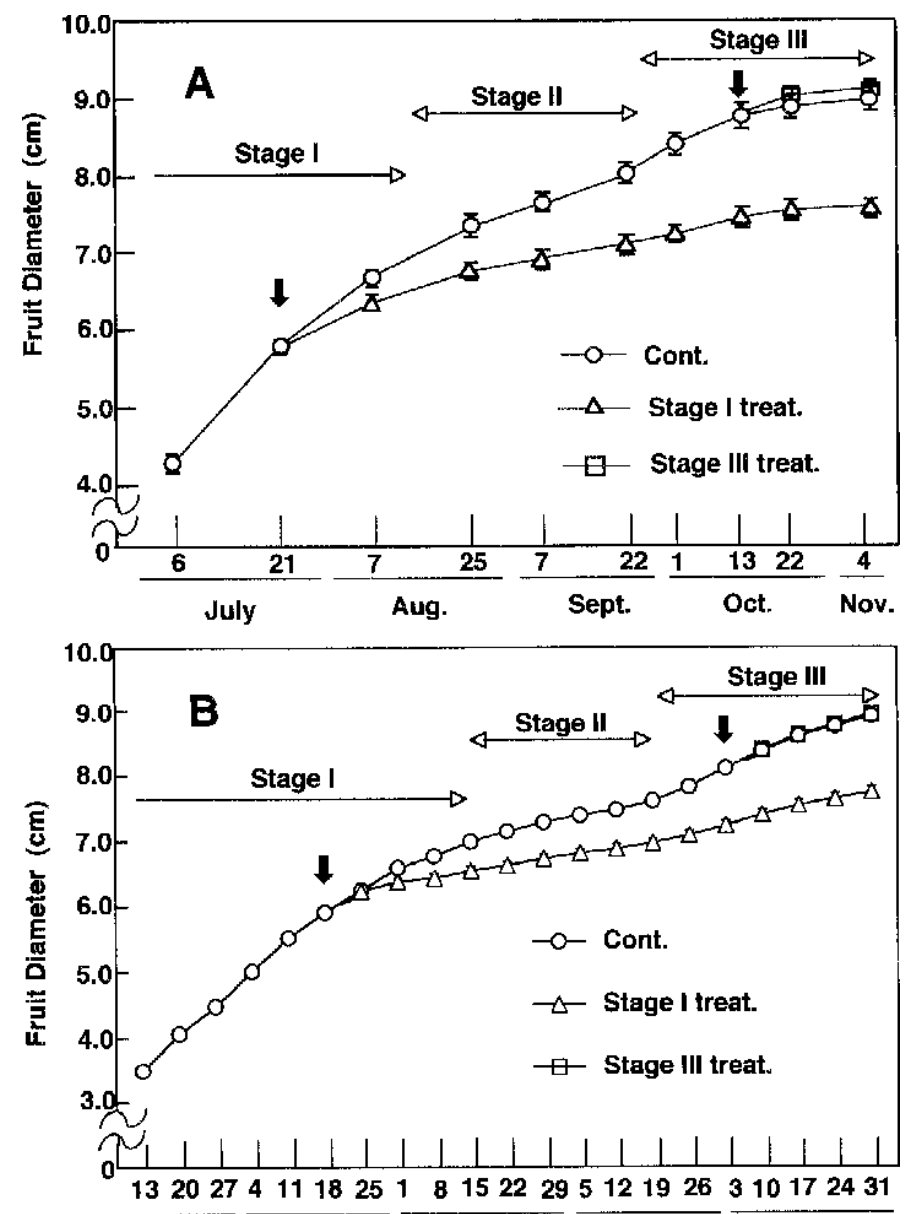

Fig. 1. Effect of calyx lobe removal at stage I or stage III on fruit growth of persimmon. Pot-grown trees were used in 1992 (A) and orchard trees in 1994 (B). Each point represents the mean of 10 fruit (1992) or 30 fruit (1994) \pm SE. The absence of an error bar indicates that it was smaller than the symbol. Arrows indicate the dates when calyx lobes were removed. 


\section{Materials and Methods}

Changes in $\mathrm{CO}_{2}$ exchange rate with calyx lobe removal. Measurements of attached fruit were conducted in 1992 using 7-year-old potgrown trees of 'Hiratanenashi' persimmon. Trees were grown outdoors and fruit-thinned in early June to adjust the leaf : fruit ratio to about 15 after full bloom in mid-May. Each tree bore four to six fruit. All four calyx lobes were manually removed in the middle of stage I (21 July) or at the beginning of stage III (13 Oct.). Growth stages I and III, separated by stage II, were defined as the period when fruit diameter increases $>0.3 \mathrm{~mm} \cdot \mathrm{d}^{-1}$ (Zheng et al., 1990).

Six to eight trees were used for each treatment. Fruits on a tree were divided into two groups after fruit thinning. One group was used for the treatments and the other was kept as the control. Each treatment group consisted of at least 10 fruit.

Fruit growth was determined by measuring the diameter of 10 fruit at about 2-week intervals after each treatment. Carbon dioxide exchange rates of 7 to 10 attached fruit were measured under field light conditions at appropriate intervals using the infrared $\mathrm{CO}_{2}$ gas analyzer of the portable photosynthesis system (LI-6200; LI-COR, Lincoln, Neb.) equipped with a 4-L chamber. At each measurement, attached fruit were carefully enclosed in the chamber to ensure that outside air did not enter during measurement. Equal numbers of control fruit per each treatment were also measured. Carbon dioxide exchange rates are expressed on a fruit basis.

Mature trees of 'Hiratanenashi' persimmon, growing at the experimental orchard of Kyoto Univ., were used for measuring detached fruit in 1994. The full bloom of these trees was almost the same as that of pot-grown trees in 1992. All four calyx lobes were manually removed in the middle of stage I (19 July) or at the beginning of stage III (3 Oct.) in 1994. After each treatment, 30 fruit were randomly labeled to measure fruit growth on the tree, and 12 fruit per treatment were sampled at about 2-week intervals to measure $\mathrm{CO}_{2}$ exchange rates.

Carbon dioxide exchange rates were measured in the orchard under dark conditions immediately after each fruit was picked, using the infrared $\mathrm{CO}_{2}$ gas analyzer of the portable photosynthesis system. A detached fruit was put into the 4-L chamber of the portable photosynthesis system, and the chamber was covered with a heavy light-proof cloth. Carbon dioxide exchange rates are

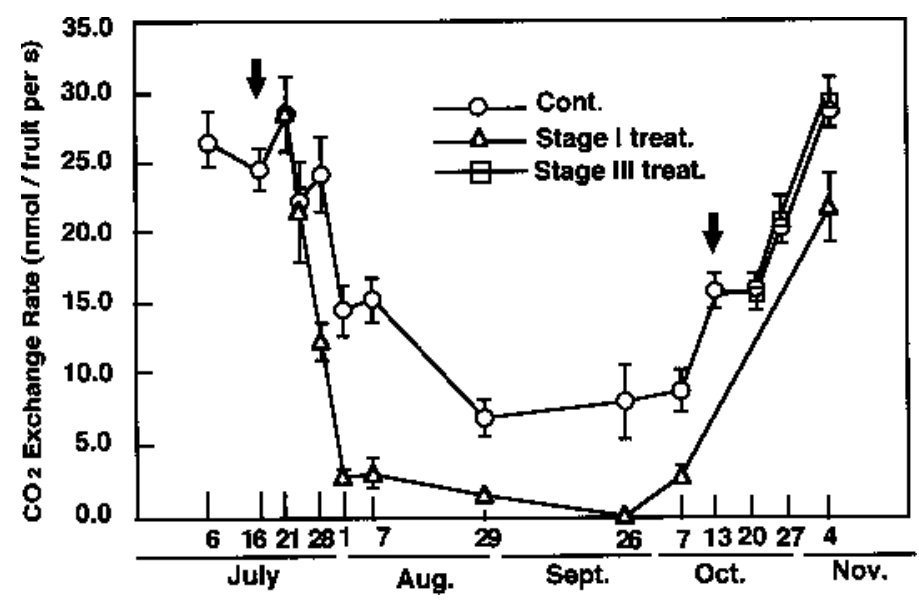

Fig. 2. Changes in $\mathrm{CO}_{2}$ exchange rate of fruit with calyx lobes removed at stage I or stage III in 1992. Carbon dioxide exchange rate of attached fruit was measured on the tree at light condition and expressed on a fruit basis. Each point represents the mean of 10 fruit \pm SE for control and stage I treatment and 7 fruit \pm SE for stage III treatment. The absence of an error bar indicates that it was smaller than the symbol. Arrows indicate the dates when calyx lobes were removed. expressed on a fruit and fresh weight basis.

Effect of scar sealing after calyx lobe removal. Calyx lobes were removed from fruit growing on mature 'Hiratanenashi' trees, at the experimental orchard of Kyoto Univ., at the beginning of stage III (5 Oct.) in 1994. Immediately after calyx removal, the scars were sealed by manually applying Vaseline. Then, 21 fruit were labeled randomly to measure fruit growth on the tree, and 6 fruit per treatment were picked at 1-week intervals to measure fruit $\mathrm{CO}_{2}$ exchange in the dark, by the same method as above.

In addition, fruit of 'Hiratanenashi', whose calyx lobes were removed in the middle of stage I (19 July) or at the beginning of stage III (3 Oct.) in 1994, were harvested on 2 Nov. Carbon dioxide exchange rate of the fruit in the dark was measured in the field immediately after fruit were picked from the tree, by the same method as above. Then, the scars of the calyx lobes were sealed with liquid paraffin, and $\mathrm{CO}_{2}$ exchange rates of the fruit in the dark were recorded again. Seven fruit were used for the measurement.
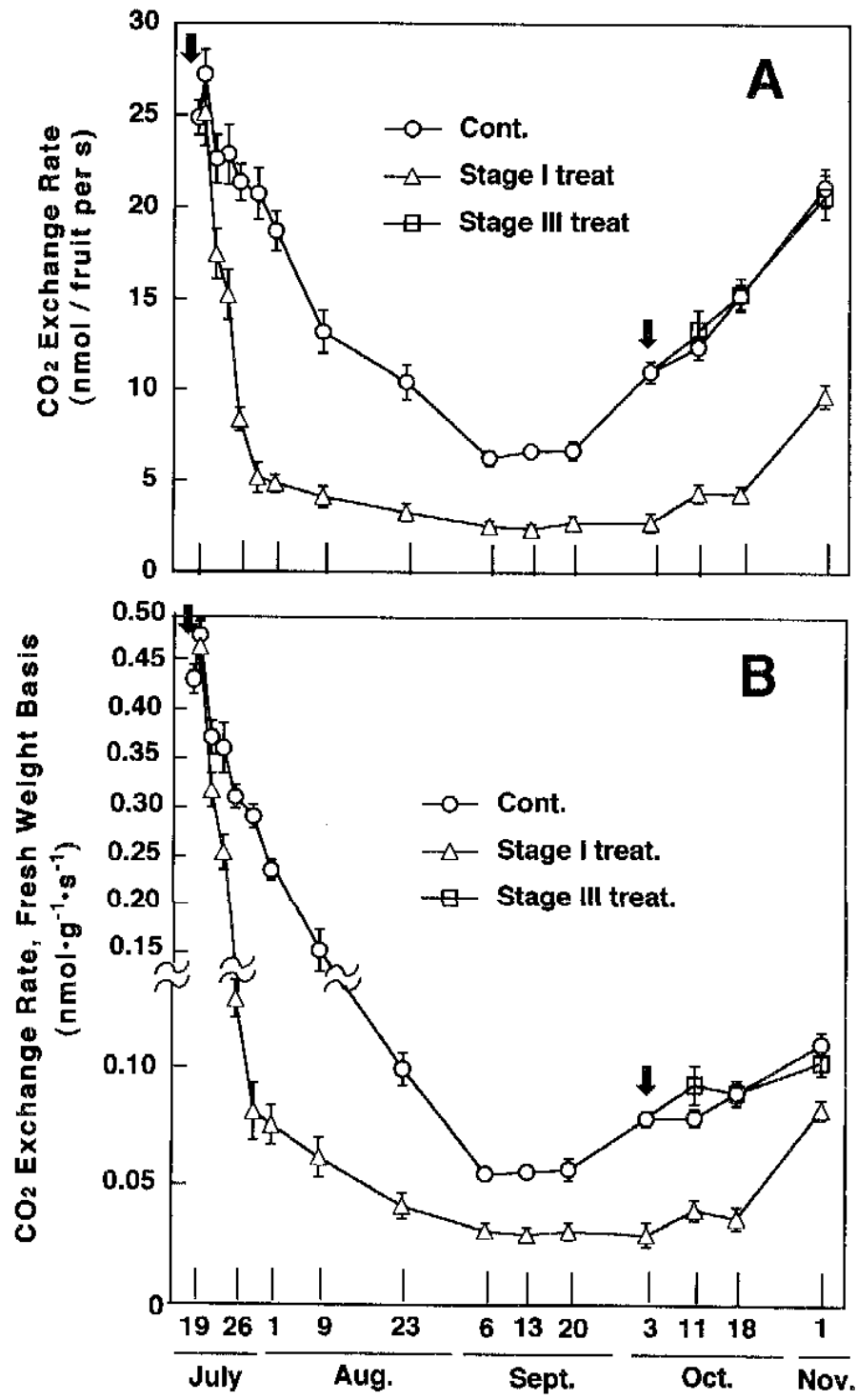

Fig. 3. Changes in $\mathrm{CO}_{2}$ exchange rates measured in the dark of fruit with calyx lobes removed at stage I or stage III in 1994. Rates are expressed on a per fruit (A) or on a fresh weight basis (B). Carbon dioxide exchange was measured immediately after fruit were picked. Each point represents the mean of 12 fruit \pm SE for each treatment. The absence of an error bar indicates that it was smaller than the symbol. Arrows indicate the dates when calyx lobes were removed. 


\section{Results}

Changes in $\mathrm{CO}_{2}$ exchange rate with calyx lobe removal. With either pot-grown trees or orchard trees, calyx lobe removal at stage I significantly inhibited fruit growth (Fig. 1). In contrast, treatment at stage III had no effect on fruit growth.

Calyx lobe removal inhibited $\mathrm{CO}_{2}$ exchange rates of attached stage I fruit (Fig. 2). High $\mathrm{CO}_{2}$ exchange rates of the control fruit in stage I gradually decreased toward the beginning of stage II and remained low during stage II. Then, $\mathrm{CO}_{2}$ exchange rate rapidly increased with the onset of stage III. However, fruit treated at stage I showed a decrease in $\mathrm{CO}_{2}$ exchange rate starting on $28 \mathrm{July}$, about 1 week after calyx lobe removal, and it rapidly dropped on 1 Aug. to a very low level, which remained during stage II. Although $\mathrm{CO}_{2}$ exchange rates of the treated fruit increased with the onset of stage III, the rise was lower relative to the control fruit. In contrast, fruit treated at stage III did not show any difference in $\mathrm{CO}_{2}$ exchange rate from the control.

The same tendency in $\mathrm{CO}_{2}$ exchange rates was detected in 1994 when rates were measured under dark conditions immediately after the fruit were picked (Fig. 3). Carbon dioxide exchange rates in the dark showed the same pattern as $\mathrm{CO}_{2}$ exchange rates in the light (Figs. 2 and 3).

Carbon dioxide exchange rates were measured under ambient temperatures, and the fluctuation of the ambient orchard temperature in 1994 is shown in Fig. 4. This suggests that the onset of $\mathrm{CO}_{2}$ exchange increase in stage III is not due to temperature effects.

Effect of scar sealing after calyx lobe removal. Sealing the scars soon after lobe removal at stage III induced an immediate inhibition of fruit growth (Fig. 5). At harvest, the diameter of fruit whose calyx lobes were removed and sealed with Vaseline were about $10 \%$ less than untreated controls. Coincident with this growth inhibition was a rapid decline of the $\mathrm{CO}_{2}$ exchange rate expressed on a fruit (Fig. 6A) or fresh weight basis (Fig. 6B). Carbon dioxide exchange of the fruit in the dark dropped soon after calyx lobes were removed and the scars were sealed with Vaseline and stayed at low levels until harvest.

Sealing the calyx lobe scars with liquid paraffin had a slight effect on $\mathrm{CO}_{2}$ exchange rates of the fruit in the dark whose calyx lobes were removed at stage I (Table 1). Carbon dioxide exchange rates of fruit whose scars were sealed with liquid paraffin were reduced about $15 \%$ compared to fruit with unsealed scars. However, sealing the lobes of fruit whose calyx lobes were removed at stage III caused an immediate drop in $\mathrm{CO}_{2}$ exchange rates in the

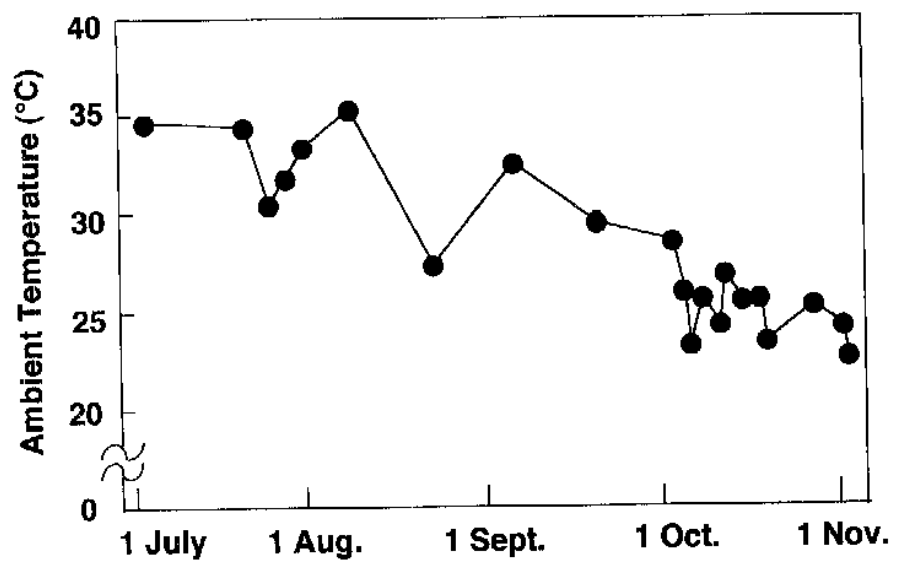

Fig.4. Fluctuation of the ambient orchard temperature among measurement dates in 1994. Each point represents the mean temperature during 12 measurements. SE of each point was smaller than the symbol. dark (Table 1). This indicates that the scars still had an important role in gas exchange, even though almost 1 month had elapsed since the calyx lobes were removed. Sealing the scars inhibited $\mathrm{CO}_{2}$ exchange rates by almost $55 \%$ and was almost the same when compared either on a per fruit or fresh weight basis (Table 1).

\section{Discussion}

Calyx lobes of the persimmon fruit have an important role in gas exchange and fruit growth. Removing the calyx lobes at stage I caused a severe decline in rates of $\mathrm{CO}_{2}$ exchange and inhibited fruit growth. The decline in $\mathrm{CO}_{2}$ exchange rates were obvious under light or dark conditions and on a fruit or fresh weight basis. A close relationship between a decline in $\mathrm{CO}_{2}$ exchange rates and an inhibition of fruit growth was also shown in fruit whose calyx lobes were removed at the beginning of stage III. This relationship only existed if the lobe scars were sealed with Vaseline immediately after calyx removal. If the scars were not sealed, removing calyx lobes at the beginning of stage III did not have an effect on $\mathrm{CO}_{2}$ exchange rates and fruit growth. This suggests that the calyx was not contributing substantially to persimmon fruit growth, even though calyx lobes are photosynthetically active (Vemmos and Goldwin, 1994). Surprisingly, the calyx lobe scars have a role in gas exchange. Sealing the scars with liquid paraffin on fruit whose calyx lobes were removed at stage III caused an immediate decline in $\mathrm{CO}_{2}$ exchange rates of fruit in the dark.

On the other hand, calyx lobes removed at stage I inhibited fruit growth and $\mathrm{CO}_{2}$ exchange rates when the scars were not sealed. It appears that quick occlusion of the scars prevents gas exchange through the scars. This assumption was confirmed by the fact that the calyx lobe scars of the fruit whose lobes were removed at stage I did not have a role in gas exchange at harvest. Sealing the calyx lobe scars with liquid paraffin of fruit harvested on 2 Nov., whose lobes were removed at stage I (19 July), showed a slight effect on $\mathrm{CO}_{2}$ exchange rates of fruit in the dark. In younger fruit, the occlusion process should have proceeded more rapidly compared with the fruit at later stages.

There is a close relationship between fruit respiration and fruit growth. Growth potential of the fruit probably is dependent on the respiration rate. As mentioned by Lambers (1985), it was commonly believed that respiration merely consumes carbohydrates

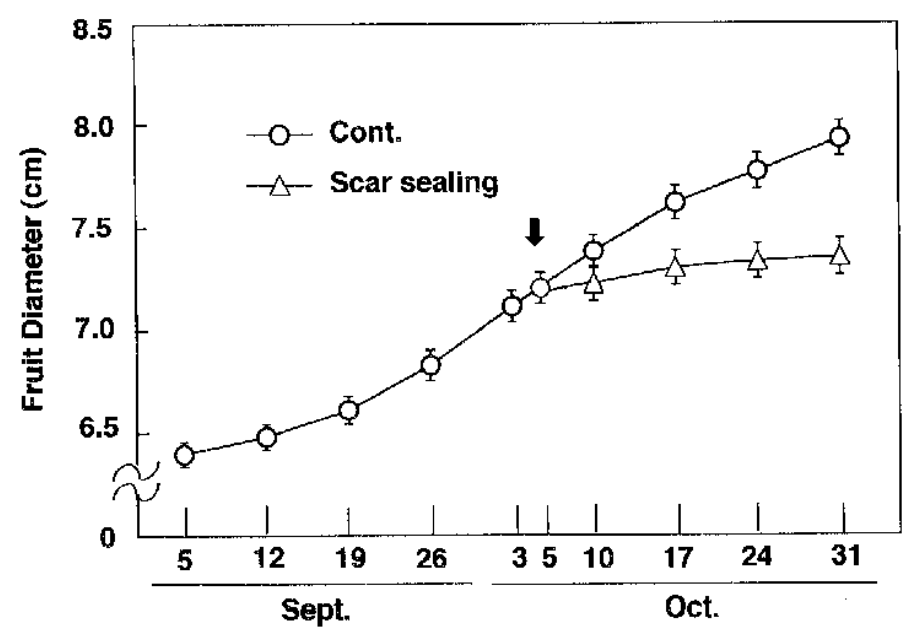

Fig. 5. Effect of scar sealing of calyx lobes on fruit growth. Calyx lobes were removed at stage III (Oct. 5) and the scars were sealed with Vaseline immediately after lobes removal. Each point represents the mean of 21 fruit \pm SE. Arrow indicates the date when calyx lobes were removed and scars were sealed with Vaseline. 

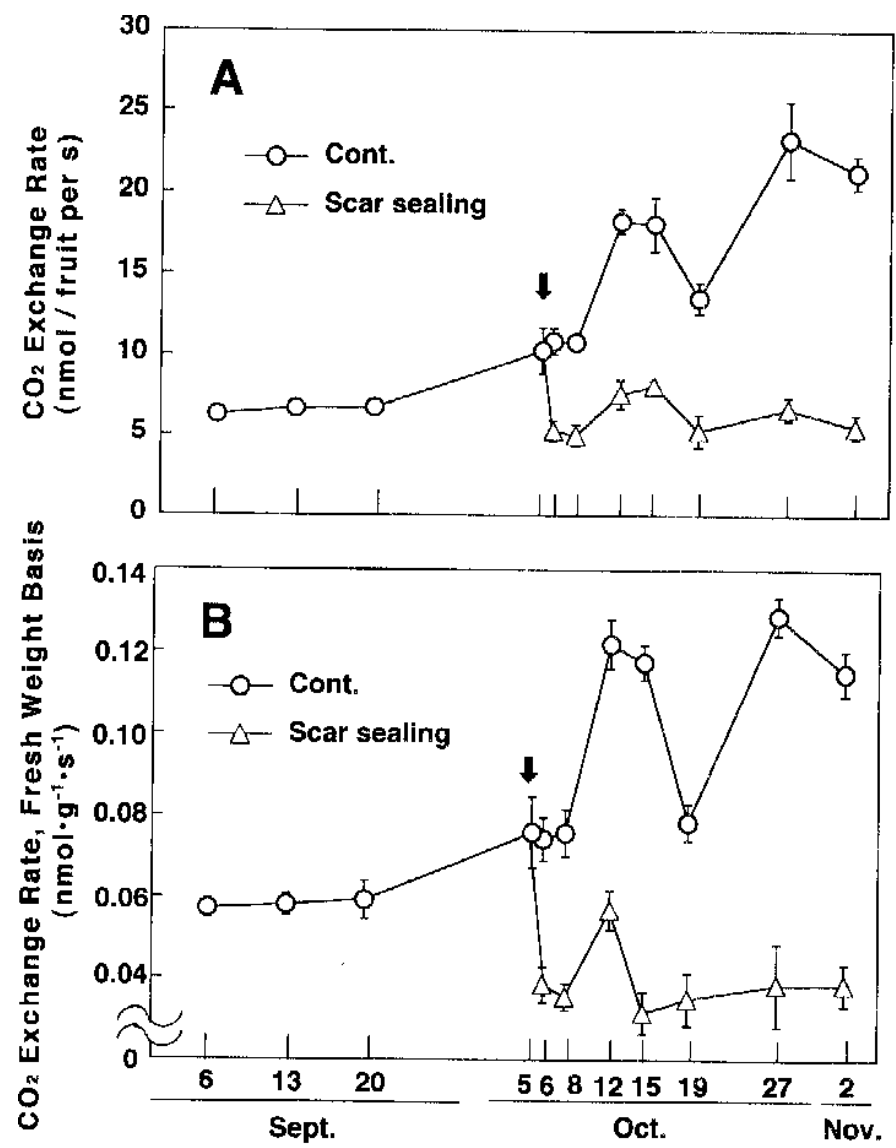

Fig. 6. Effect of scar sealing on $\mathrm{CO}_{2}$ exchange rates measured in the dark. Calyx lobes were removed at stage III (Oct. 5) and the scars were sealed with Vaseline immediately after lobes removal. Carbon dioxide exchange rates are expressed on a fruit basis (A) or on a fresh weight basis $(\mathbf{B})$. Carbon dioxide exchange was measured within $10 \mathrm{~min}$ after fruit was picked. Each point represents the mean of 6 fruit \pm SE for each treatment. The absence of an error bar indicates that it was smaller than the symbol. Arrow indicates the date when calyx lobes were removed and scars were sealed with Vaseline.

that could otherwise have been used for growth, thereby decreasing the yield. In fact, Wilson (1982) showed that the fast-growing lines of Lolium perenne 'S23' had a slower rate of dark respiration of mature leaves, on a unit dry weight basis, compared with the slow-growing lines. In Citrus, Blanke and Bower (1991) demonstrated that young 'Valencia' fruit with small fruit potential had a higher respiration rate in the dark than fruit without small fruit potential. However, respiration is the source of metabolic energy to be used in the various processes determining yield. According to Pavel and DeJong (1993), respiration rates in the dark for peach fruit increased rapidly early in the season. It remained relatively constant at midseason and then increased in mature fruit. They suggested that the rapid increase of respiration rates may be related to high metabolic activities in young and mature fruit.

In our experiments, $\mathrm{CO}_{2}$ exchange rates in the dark rapidly increased in control fruit with the onset of growth stage III. Since the orchard temperature gradually decreased toward fall, these increased $\mathrm{CO}_{2}$ exchange rates did not depend on the ambient temperature. The rise in $\mathrm{CO}_{2}$ exchange rates in the dark at stage III appears to be intrinsic. Climacteric-type fruit have a rise of respiration at the onset of ripening. However, the rise in respiration of persimmon fruit during stage III does not seem to be a climacteric rise, because it appeared about 2 weeks before ripening and continued until harvest. This rise seems to be associated with the final swell of the fruit. Carbon dioxide exchange rates in the dark may reflect the sink activity of the fruit. When a fruit has a high respiration rates, the fruit may be a strong sink because of its high metabolic activity. De novo synthesis of sugar metabolizing enzymes, such as acid invertases, may be necessary to maintain a strong sink activity by the fruit. Uptake of transported assimilates by the fruit may also include energy-dependent processes.

\section{Literature Cited}

Blanke, M.M. and J.P. Bower. 1991. Small fruit problem in Citrus trees. Trees 5:239-243. Hirano, K., K. Yonemori, and A. Sugiura. 1995. Involvement of sugar metabolism in persimmon growth inhibition by calyx lobe removal. J. Amer. Soc. Hort. Sci. 120:7577.

Kitagawa, H. and P.G. Glucina. 1984. Persimmon culture in New Zealand. Science Information Publishing Center, Wellington, N.Z. p. 25-26.

Lambers, H. 1985. Respiration in intact plants and tissues: Its regulation and dependence on environmental factors, metabolism and invaded organisms, p. 418-473. In: R. Douce and D.A. Day (eds.). Higher plant cell respiration. Springer-Verlag, Berlin.

Pavel, E.W. and T.M. DeJong. 1993. Seasonal $\mathrm{CO}_{2}$ exchange patterns of developing peach (Prunus persica) fruits in response to temperature, light and $\mathrm{CO}_{2}$ concentration. Physiol. Plant. 88:322-330.

Taira, S., A. Sugiura, and T. Tomana. 1987. Relationships between natural flesh darkening and polyphenoloxidase activity in Japanese persimmon (Diospyros kaki Thunb.) fruits. J. Jpn. Soc. Food Sci. Technol. 34:612-615.

Vemmos, S.N. and G.K. Goldwin. 1994. The photosynthetic activity of Cox's Orange Pippin apple flowers in relation to fruit setting. Ann. Bot. 73:385-391.

Westwood, M.N. 1978. Temperate-zone pomology, p. 203-208. W.H. Freeman, San Francisco.

Wilson, D. 1982. Effect of selection for dark respiration rate of mature leaves on crop yields of Lolium perenne cv. S23. Ann. Bot. 49:313-320.

Yonemori, K., K. Hirano and A. Sugiura. 1995. Growth inhibition of persimmon fruit caused by calyx lobe removal and possible involvement of endogenous hormones. Scientia Hort. 61:37-45.

Zheng, G.H., S. Taira, K. Yonemori, and A. Sugiura. 1990. Fruit growth and ripening of Japanese persimmons (Diospyros kaki Thunb.) grown at two locations with different temperature conditions. J. Jpn. Soc. Hort. Sci. 59:471-477.

Zimmermann, M.H. and H. Ziegler. 1975. List of sugars and sugar alcohols in sieve-tube exudates, p. 480-503. In: M.H. Zimmermann and J.A. Milburn (eds.). Transport in plants. I. Phloem transport. Springer-Verlag, Berlin.

Table 1. Effect of scar sealing with liquid paraffin on $\mathrm{CO}_{2}$ exchange rates in the dark of fruit whose calyx lobes were removed at growth stage I (on 19 July) or growth stage III (on 3 Oct.).

\begin{tabular}{|c|c|c|c|c|}
\hline & \multicolumn{4}{|c|}{$\mathrm{CO}_{2}$ exchange rate in the dark ${ }^{\mathrm{z}}$} \\
\hline & \multicolumn{2}{|c|}{ Per fruit (nmol/fruit per s) } & \multicolumn{2}{|c|}{ Per fresh wt $\left(\mathrm{nmol} \cdot \mathrm{g}^{-1} \cdot \mathrm{s}^{-1}\right)$} \\
\hline & Just before sealing & Soon after sealing $^{y}$ & Just before sealing & Soon after sealing \\
\hline Calyx lobes removed at Stage I & $\begin{array}{c}11.94 \pm 1.26^{\mathrm{x}} \\
(100)^{\mathrm{w}}\end{array}$ & $\begin{array}{c}10.03 \pm 1.17 \\
(83.9)\end{array}$ & $\begin{array}{c}0.109 \pm 0.013 \\
(100)\end{array}$ & $\begin{array}{c}0.092 \pm 0.014 \\
(84.8)\end{array}$ \\
\hline Calyx lobes removed at Stage III & $\begin{array}{c}20.91 \pm 2.32 \\
(100)\end{array}$ & $\begin{array}{c}9.31 \pm 1.15 \\
(44.5)\end{array}$ & $\begin{array}{c}0.111 \pm 0.007 \\
(100)\end{array}$ & $\begin{array}{c}0.050 \pm 0.005 \\
(44.8)\end{array}$ \\
\hline
\end{tabular}

${ }^{\mathrm{z}}$ Carbon dioxide exchange was measured on 2 Nov. before and after scar sealing with liquid paraffin at the ambient temperature.

yEach measurement was done within 5 min after scars were sealed with liquid paraffin.

${ }^{x}$ Mean \pm SE $(n=7)$.

${ }^{\text {w}}$ Figures in parentheses indicate relative values before and after the scars were sealed with liquid paraffin. 